Case Report

Volume 1 - Issue 2

\title{
Neurogenic Pulmonary Edema Caused by Subarachnoid Hemorrhage: A Case Report
}

\author{
Hongyang Chen ${ }^{1}$, Hongyu Zhou ${ }^{1}$, Zining Wang ${ }^{2}$, Weiyi Zhang ${ }^{1}$, Tao Zhu ${ }^{1, *}$ \\ ${ }^{1}$ Department of Anesthesiology, West China Hospital, Sichuan University, No.37 Guoxue Street, Chengdu 610041, China \\ ${ }^{2}$ West China school of Clinical medicine, Sichuan University, Chengdu, Sichuan, China \\ *Corresponding author: Tao Zhu, Department of Anesthesiology, West China Hospital, Sichuan University, No.37 Guoxue Street, \\ Chengdu 610041, China
}

Received date: 30 November, 2021

Accepted date: 8 December, $2021 \mid$

Published date: 24 December, 2021

Citation: Chen H, Zhou H, Wang Z, Zhang W, Zhu T. (2021) Neurogenic pulmonary edema caused by subarachnoid hemorrhage: a case report. J Anaesth Anesth Drug 1(2): doi https://doi.org/10.54289/JAAD2100106

Copyright: (C) 2021 Chen H, et al. This is an open-access article distributed under the terms of the Creative Commons Attribution License, which permits unrestricted use, distribution, and reproduction in any medium, provided the original author and source are credited.

Keywords: Neurogenic pulmonary edema; Anesthesiology; Subarachnoid hemorrhage

Abbreviations: BP: Blood Pressure, RP: Respiratory Rate, SPO2: Oxygen Saturation, GCS: Glasgow Coma Scale, HR: Heart Rate, Hct: Hematocrit, PH: Pondus Hydrogenii, PaCO2: Partial Pressure of Carbon Dioxide, BE: Base Excess, FiO2: Fraction of inspiration Oxygen, ECG: Electrocardiogram, ETCO2: End-Tidal Carbon Dioxide, Lac: Lactic Acid, PCV-VG: Pressue Controled Ventilation-Volume Guarantee, VT: Tidal Volume, PEEP: Positive end expitrtory pressure, NICU: Neuroconscious Intensive Care Unit, NPE: Neurogenic Pulmonary Edema.

\section{Introduction:}

Neurogenic pulmonary edema is a serious and lifethreatening complication caused by central nervous system diseases, excluding cardiogenic pulmonary edema, other causes of pulmonary edema, lung injury, etc. The lack of specific diagnostic criteria for NPE and the lack of awareness among clinicians often lead to underdiagnosis and misdiagnosis. The disease progresses rapidly with poor prognosis and high mortality [1]. In this paper, we report a patient with a ruptured right middle cerebral artery aneurysm causing subarachnoid hemorrhage, who developed neurogenic pulmonary edema and underwent elective aneurysm clamping under general anesthesia. The relevant perioperative management is reported as follows, and the anesthesia management of patients with neurogenic pulmonary edema is analyzed in the context of the relevant literature.

\section{Case Report:}

\section{Medical History}

The patient was a 69 -year-old male, with a height of $175 \mathrm{~cm}$ and a weight of $79 \mathrm{~kg}$, who was admitted to the emergency department of our hospital due to "sudden disturbance of consciousness for more than 4 days". The patient was in shallow coma, with blood pressure (BP) of 163/117 mmHg, heart rate (HR) of 99 beats/min, Respiratory rate (RR) of 20 breaths/min, and oxygen saturation (SPO2) was 93\% while he received $5 \mathrm{~L} / \mathrm{min}$ oxygen through a nasal cannula, and the GCS (Glasgow coma scale) was 10 points. External cranial CT of another hospital showed subarachnoid hemorrhage, and whole brain angiography revealed a right middle cerebral aneurysm. The diagnosis of "right middle cerebral artery aneurysm (near the insula), subarachnoid hemorrhage and hypertension" was considered, and the an patient was admitted to the neurosurgery department, and history of hypertension, diabetes mellitus, or heart disease. 
Preoperative electrocardiogram showed sinus rhythm, with ST-segment T-wave changes, and external chest radiograph of other hospital showed increased texture in both lungs. He was admitted to the emergency department with routine blood: Hemoglobin(Hb) of $181 \mathrm{~g} / \mathrm{L}$, Hematocrit(Hct) of 0.53 , Troponin-T of $17.4 \mathrm{ng} / \mathrm{ml}$. Blood gas analysis: Pondus Hydrogenii(pH) of 7.46, Partial Pressure of Oxygen $(\mathrm{PaO} 2)$ of $62 \mathrm{mmHg}$, Partial Pressure of Carbon Dioxide(PaCO2) of $22.5 \mathrm{mmHg}$, Base Excess(BE) of $-5.34 \mathrm{mmol} / \mathrm{L}$.

\section{Anesthesia and operation procedure}

After admission, cranial hematoma removal was proposed as an elective procedure, and relevant investigations and preoperative preparations were completed. During the preanesthesia visit, the patient was in shallow coma, with BP of 126/84 $\mathrm{mmHg}$, HR of 104 beats/min, RR of 27-30 breaths $/ \mathrm{min}, \mathrm{SpO}_{2} 93 \%$ (the patient was receiving 8-9 L/min oxygen via mask), and Urapidil Hydrochloride was pumped to control blood pressure, and the GCS was 9 points. At 11:00 p.m. of the same night after admission, the patient suddenly developed deepening consciousness and decreased blood pressure (considering re-rupture of the aneurysm). The chief resident of the Department of Anesthesiology was contacted for emergency tracheal intubation and emergency craniotomy for hematoma removal was proposed. On examination, dopamine $\left(8-10 \mathrm{ug} \cdot \mathrm{kg}^{-1} \cdot \mathrm{min}^{-1}\right)$ to maintain blood pressure to $131 / 90 \mathrm{mmHg}$, $\mathrm{HR}$ of 105 beats/min, $\mathrm{SpO}_{2}$ of $95 \%$ (Fraction of inspiration $\mathrm{O}_{2}\left(\mathrm{FiO}_{2}\right) 100 \%$ ), and the GCS was 5 points.

The patient was admitted to the operating room at 11:30 p.m. with routine Electrocardiogram (ECG) monitoring, BP 92/75 mmHg (no vasoactive drugs), HR 99 beats/min, Spo2 94\% (the patient was receiving oxygen through invasive ventilator with $\mathrm{FiO}_{2} 60 \%$ ), RR 12 of beats/min, and the GCS was 5 points, end-tidal carbon dioxide $\left(\mathrm{ETCO}_{2}\right)$ was $36 \mathrm{mmHg}$ and airway pressure was $23 \mathrm{cmH}_{2} \mathrm{O}$. Anesthesia induction: intravenous injection of Propofol 50mg, Sufentanil 20ug, Cisatracurium 14mg. Anesthesia maintenance: Propofol TCI mode $3 \mathrm{ug} / \mathrm{ml}$ and Remifentanil $0.1 \mathrm{ug} \cdot \mathrm{kg}^{-1} \cdot \mathrm{min}^{-1}$ continuous pumping. A few wet rales were heard in both lungs, and sputum was aspirated. The left radial artery was punctured and cannulated, invasive blood pressure monitoring was continued, an arterial blood gas reveals a $\mathrm{pH}$ of $7.25, \mathrm{~Pa}_{2}$ of 104. $2 \mathrm{mmHg}$ (the patient was receiving oxygen through invasive ventilator with $\left.\mathrm{FiO}_{2} 60 \%\right), \mathrm{PaCO}_{2}$ of $45.6 \mathrm{mmHg}$, BE of -7. $74 \mathrm{mmol} / \mathrm{L}$, Lactic Acid (Lac) of $1.6 \mathrm{mmol} / \mathrm{L}$. The operation started at 00:05 a.m. and 250ml of mannitol and $80 \mathrm{mg}$ of methylprednisolone were given intravenously before craniotomy. Half an hour later, $\mathrm{SpO}_{2}$ gradually decreased to $81 \%$ and airway pressure rose to $34 \mathrm{cmH}_{2} \mathrm{O}$. (Ventilator mode: Pressue Controled Ventilation-Volume Guarantee(PCV-VG) mode, with $\mathrm{FiO}_{2}$ of $60 \%$, Tidal Volume(VT) of $550 \mathrm{ml}$, RR of 12 breaths/min, $\mathrm{ETCO}_{2}$ of 239 $\mathrm{mmHg}$ ).Immediately rechecked blood gas analysis with $\mathrm{pH}$ of $7.23, \mathrm{~Pa} 02$ of $57.6 \mathrm{mmHg}$ (the patient was receiving oxygen through invasive ventilator with $\mathrm{FiO} 260 \%$ ), $\mathrm{PaCO} 2$ of $50.3 \mathrm{mmHg}$, BE of $-7.27 \mathrm{mmol} / \mathrm{L}$, and $\mathrm{Lac}$ of $1.8 \mathrm{mmol} / \mathrm{L}$. Confirming normal tracheal tube depth and no discounting, adjusted inhaled oxygen concentration to $100 \%$, auscultated obvious wet rales in both lungs, aspirated pink secretions, $\mathrm{SpO}_{2}$ rose to $93 \%$, airway pressure of $24 \mathrm{cmH}_{2} \mathrm{O}$. And total liquid intake was $900 \mathrm{ml}$, bleeding was $100 \mathrm{ml}$ and urine volume was $250 \mathrm{ml}$. The respiratory parameters were adjusted (PCV-VG mode, $\mathrm{FiO}_{2}$ of $100 \%$, VT of $400 \mathrm{ml}$, RR of 16 breaths $/ \mathrm{min}, \mathrm{ETCO}_{2}$ of $40 \mathrm{mmHg}$, Positive end expitrtory pressure (PEEP) of $8 \mathrm{cmH}_{2} \mathrm{O}, \mathrm{SpO}_{2}$ gradually increased to $96 \%$, and Furosemide 10mg was added. At 02:15 when the main surgeon performed intracranial hematoma removal, the patient had a large bleeding volume and at the same time, blood pressure dropped to $72 / 39 \mathrm{mmHg}$ and heart rate increased to 138 beats/min. Immediately, the infusion rate was accelerated, red blood cell suspension was infused, while $7 \mathrm{~F}$ double-lumen central venous placement was performed through the left femoral vein. Then Norepinephrine and Epinephrine were continuously pumped to maintain blood pressure, which was maintained at 110 116/79 84 mmHg, heart rate was controlled at 80 100 beats/min and $\mathrm{SpO}_{2}$ was maintained at $95 \%$. And then the vital signs were stable. The operation ended at 05:20 a.m. and the patient was transferred to the Neuroconscious Intensive Care Unit (NICU) with a tracheal minutes. The total intraoperative intake was6100 ml, red blood cell suspension $4 \mathrm{u}$, fresh frozen plasma $400 \mathrm{ml}$, autologous recovered blood $600 \mathrm{ml}$. And bleeding was about $1800 \mathrm{ml}$, and urine volume was $1900 \mathrm{ml}$. 
At the time of admission to the NICU, norepinephrine $(0.5$ $1 \mathrm{ug} / \mathrm{kg} \cdot \mathrm{min})$ and epinephrine (0.05-0.1ug/kg.min) were pumped, initial vital signs include BP 110/70 mmHg, HR 95 beats/min, R 14 breaths/min, $\mathrm{SPO}_{2} 78 \%$ (the patient was receiving oxygen through invasive ventilator with $\mathrm{FiO}_{2} 60 \%$ ) and the GCS was 3 points, sputum was administered, and $\mathrm{SPO}_{2}$ rose to $92 \%$ after adjusting the inhaled oxygen concentration to $100 \%$. After the patient was admitted to the NICU, he was treated with sputum aspiration, diuresis, reduction of intracranial pressure, cardiac strengthening, maintenance of circulation, and maintenance of electrolyte balance. Postoperative review of chest radiograph: reduced translucency of both lungs, right lung predominant, increased and blurred texture of both lungs, possible scattered infection in both lungs. Bedside fibrinoscopy: large amount of pale red thin sputum was seen in the left and right main airways and lower lobe airways of both lungs, diffuse mucosal edema was seen in both lungs, and a total of $20 \mathrm{ml}$ of pale red thin sputum was aspirated from both lungs. Myocardial markers were rechecked, uromodulin was $2015 \mathrm{pg} / \mathrm{ml}$ and troponin $\mathrm{T}$ was 30. $9 \mathrm{ng} / \mathrm{ml}$. At 5:00 p.m. on the day of surgery, the patient again showed brain herniation manifestations such as decreased heart rate and blood pressure, and was immediately given mannitol $250 \mathrm{ml}$ intravenous drip and rechecked cranial $\mathrm{CT}$, the examination results showed that the patient had intracranial hemorrhage again after the operation, and explained to the patient's family that the condition was heavy and the prognosis was poor, the patient's family asked to go back to the local hospital to continue treatment, and signed for automatic discharge at 05:30 p.m.

\section{Discussion}

Neurogenic pulmonary edema has a rapid onset, rapid progression, and high mortality rate, with acute respiratory distress and hypoxemia as the main clinical manifestations. The common causes of NPE include EV71 virus infection, subarachnoid hemorrhage, traumatic cranial injury, and brain tumor. The mechanism of neurogenic pulmonary edema is currently considered to be the excessive activation of sympathetic nerves after hypothalamic or medulla oblongata injury, which leads to the massive release of catecholamines (catecholamine storm), resulting in systemic vasoconstrict- tion, elevated vascular resistance of the body circulation, elevated left atrial pressure, and increased pulmonary capillary hydrostatic pressure. In addition, dramatic changes in hemodynamics can also directly damage the pulmonary capillary endothelium causing fluid leakage and resulting in pulmonary edema. A study found that children in the group with intracranial pressure $>15 \mathrm{mmHg}$ had increased extravascular pulmonary water index and lung permeability, and decreased systemic vascular resistance, cerebral perfusion, and oxygenation index [2].

Neurogenic pulmonary edema lacks specific diagnostic criteria, and the diagnosis of neurogenic pulmonary edema is considered in patients with clinical presence of central nervous damage, pink foamy sputum, bilateral pulmonary infiltrative shadow on chest radiograph, and oxygenation index $<200 \mathrm{mmHg}$, after excluding other causes such as cardiopulmonary [3]. In this case, the patient had persistent intraoperative aspiration of pink foamy sputum, wet rales in both lungs, oxygenation index of $173 \mathrm{mmHg}$ with progressive decrease and persistent uncorrectable hypoxemia, no previous history of cardiopulmonary and other diseases, no massive infusion, allergy, etc. The diagnosis of NPE was clear. In this case, the patient abandoned treatment on the first postoperative day due to severe disease. Some studies have shown that early diagnosis can improve patient prognosis, [4] however, there are no specific clinical manifestations in the early stage of NPE, and the diagnosis is relatively difficult. Our patient was found to have increased texture in both lungs at the time of consultation at our hospital 4 days after the onset of the disease and had a poor prognosis.

The patient in this case had a preoperative Hunt-Hess classification of grade III, and the preoperative chest radiograph only indicated increased pulmonary texture in both lungs and the electrocardiogram was sinus rhythm with ST-T changes. The patient was preoperatively comatose, on high concentration mask oxygen, with sPO2 fluctuating at $90 \%$, coarse breath sounds in both lungs, scattered wet rales early and no obvious specific clinical manifestations,

making diagnosis of NPE difficult. In a prospective, observational study, an APACHE II score $\geq 20$, IL-6 $>40$ $\mathrm{pg} / \mathrm{mL}$ was found to be an independent risk factor for the development of NPE, [5] and our patient had an APACHE II 
score of 31 and an increased troponin. The literature reports that in patients with subarachnoid hemorrhage, excessive sympathetic excitation, catecholamines can directly damage the myocardium and elevated troponin is seen in approximately $20-68 \%$ of patients. In studies of adults with subarachnoid hemorrhage, abnormal ECG was found to predict the development of NPE [6] and was associated with risk such as poor prognosis [7].

Although the exacerbation of the patient's condition in this case was due to postoperative rebleeding, symptoms related to neurogenic pulmonary edema appeared right after the start of the first operation. After the diagnosis was clarified intraoperatively, tachypnea was added immediately and respiratory parameters were adjusted to improve oxygenation, including low tidal volume ventilation and PEEP to maintain normal oxygen supply and carbon dioxide levels. Methylprednisolone was also given to improve vascular permeability, but the use of glucocorticoids is still controversial [8]. Katharina M. Busl et al [9]. Concluded that the main treatment options for NPE are adequate sedation and analgesia, reduction of sympathetic excitability, reduction of intracranial pressure, and supportive treatment for pulmonary edema, including volume management, ventilation strategies, and optimal oxygen supply. Reducing intracranial pressure while ensuring adequate circulating blood volume is a perioperative challenge, and ultrasound and PICCO monitoring are useful as a guide. The presence or absence of pulmonary edema can be determined by ultrasound detection of B-line and guides intraoperative fluid management [10].

Other measures have been found in previous experiments to reduce the occurrence of NPE. In animal experiments, intrathecal lidocaine decreased sympathetic excitability, lowered intracranial pressure, and reduced cardiopulmonary complications, neurogenic pulmonary edema [11]. It has also been found that nitric oxide [12] and cytokines [13] reduce pulmonary capillary permeability, thereby reducing the occurrence of NPE.

Neurogenic pulmonary edema is not uncommon in neurosurgical patients with aneurysmal subarachnoid hemorrhage, which usually occurs on the same day of hemorrhage and subsides in the following days. However, if a re-rupture of the aneurysm occurs, the condition can worsen dramatically and progress rapidly, with a poor prognosis. Therefore, early detection and early treatment of neurogenic pulmonary edema disease are more effective, but there are no specific manifestations in the early stage, which makes the diagnosis more difficult. Therefore, clinical awareness of this disease needs to be improved.

\section{Declaration}

\section{Acknowledgments}

The authors appreciate the patient's consent to this case report.

\section{Funding}

This report was supported by National Key RESEARCH and Development Program (2020YFC2005303).

\section{Availability of data and materials}

The datasets supporting the conclusions of this article are included within the article.

\section{Author's contributions}

Dr.Hongyang Chen performed the anesthesia of the operation and he collected the medical records of the patient; Dr. Hongyu Zhou and Mr. Zining Wang took responsibility for investigation and data curation; Dr.Hongyang Chen and Dr.Weiyi Zhang drafted and revised the manuscript.

All authors read and approved the final manuscript.

\section{Competing interests}

The authors declare that they have no competing interests.

\section{Consent for publication}

Written informed consent for publication of their clinical details and clinical images was obtained from the patient $\mathrm{A}$ copy of the written consent is available for review by the Editor of this journal.

\section{Ethics approval and consent to participate}

Not applicable

\section{Reference:}

1. Kahn JM, Caldwell EC, Deem S, Newell DW, Heckbert SR, et al. (2006) Acute lung injury in patients with subarachnoid hemorrhage: incidence, risk factors, and outcome. Crit Care Med. 34(1): 196-202.

2. Cecchetti C, Elli M, Stoppa F, Di Nardo M, Pasotti E, et al. (2013) Neurogenic pulmonary edema and variations of hemodynamic volumetric parameters 
in children following head trauma. Minerva Anestesiol. 79(10): 1140-1146.

3. Finsterer J. (2019) Neurological Perspectives of Neurogenic Pulmonary Edema. Eur Neurol. 81(1-2): 94-102.

4. Davison DL, Terek M, Chawla LS. (2012) neurogenic pulmonary edema. Crit Care. 16(2): 212.

5. Junttila E, Ala-Kokko T, Ohtonen P, Vaarala A, Karttunen A, et al. (2013) Neurogenic pulmonary edema in patients with nontraumatic intracerebral hemorrhage: predictors and association with outcome. Anesth Analg. 116(4): 855-861.

6. Chen WL, Huang CH, Chen JH, Tai HC, Chang SH, et al. (2016) ECG abnormalities predict neurogenic pulmonary edema in patients with subarachnoid hemorrhage. Am J Emerg Med. 34(1): 79-82.

7. Van der Bilt IAC, Hasan D, Vandertop WP, Wilde AA, Algra A, et al. (2009) Impact of cardiac complications on outcome after aneurysmal subarachnoid hemorrhage: a meta-analysis. Neurology. 72(7): 635-642.

8. Brain Trauma F, American Association of Neurological S, Congress of Neurological S, Joint Section on N, Critical Care AC, et al. (2007)
Guidelines for the management of severe traumatic brain injury. XV Steroids. J Neurotrauma. 24 Suppl 1: S91-95.

9. Busl KM, Bleck TP. (2015) Neurogenic Pulmonary Edema. Crit Care Med. 43(8): 1710-1715.

10. Dai Q, Su L. (2014) neurogenic pulmonary edema caused by spontaneous cerebellar hemorrhage: A fatal case report. Surg Neurol Int. 5: 103.

11. Hall SR, Wang L, Milne B, Ford S, Hong M. (2002) Intrathecal lidocaine prevents cardiovascular collapse and neurogenic pulmonary edema in a rat model of acute intracranial hypertension. Anesth Analg. 94(4): 948-953.

12. Hamdy O, Maekawa H, Shimada Y, Feng GG, Ishikawa N. (2001) Role of central nervous system nitric oxide in the development of neurogenic pulmonary edema in rats. Crit Care Med. 29(6): 1222-1228.

13. Avlonitis VS, Wigfield CH, Kirby JA, Dark JH. (2005) the hemodynamic mechanisms of lung injury and systemic inflammatory response following brain death in the transplant donor. Am J Transplant. 5(4 Pt 1): 684-693. 